\title{
Synthesis and Characterization of Nickel-doped Manganese Dioxide Electrode Materials for Supercapacitors
}

\author{
Jie Dong, Zhenzhong Hou, Qiuli Zhao and Qinghao Yang* \\ School of Materials Science and Engineering, Xi' an University of Science and Technology, Xi' an, China
}

\begin{abstract}
Nickel-doped manganese dioxide $\left(\mathrm{Ni}-\mathrm{MnO}_{2}\right)$ synthesized by sol-gel method has been used as an electrode material for supercapacitors. The structure and electrochemical properties of the samples were characterized by X-ray diffraction (XRD), scanning electron microscopy (SEM), cyclic voltammetry (CV), galvanostatic charge-discharge (GCD) and electrochemical impedance spectrometry (EIS). Results showed that the nickel-doped manganese dioxide sample exhibited irregular particles with the diameter of about 500 $\mathrm{nm}$. The crystallographic structure of $\mathrm{MnO}_{2}$ was the poorly crystallized $\gamma-\mathrm{MnO}_{2}$. The doping ratio had a great influence on the electrochemical properties of the materials. When the molar ratio of Ni/Mn was 3/100, the specific capacitance of $\mathrm{Ni}-\mathrm{MnO}_{2}$ achieved to $252.61 \mathrm{~F} / \mathrm{g}$. After 2000 charge/discharge cycles, the specific capacitance of $\mathrm{Ni}-\mathrm{MnO}_{2}$ was still maintained at $74.36 \%$, which was attributed to its excellent cycling stability.
\end{abstract}

\section{Introduction}

Supercapacitor is a new type of energy storage device that combines the advantages of both batteries and conventional capacitors. As an energy storage device, supercapacitor exhibits many advantages such as high power density, long cycle life, excellent reversibility and environmental friendliness. ${ }^{[1,2]}$ It has been well developed in the field of electric vehicles with clean energy as the main energy source.

Currently, the most widely used electrode materials include carbon materials $s^{[3,4]}$, conductive polymers ${ }^{[5,6]}$, transition metal oxides ${ }^{[7,8]}$. Among them, transition metal oxides are considered to be preeminent electrode materials due to their large specific capacitance and fast redox kinetics. $\mathrm{RuO}_{2}$ is an excellent electrode material with a specific capacitance of up to $720 \mathrm{~F} / \mathrm{g}$, but the expensive price and intrinsic toxicity limit its practical application. ${ }^{[8]}$ Therefore, people are looking for transition mental compounds of low cost to replace $\mathrm{RuO}_{2}$. $\mathrm{MnO}_{2}$ has similar properties to $\mathrm{RuO}_{2}$, which is favored by many researchers, because of its abundance, superior environmental and theoretical specific capacitance up to $1370 \mathrm{~F} / \mathrm{g}^{[9,10]}$. However, the conductivity of pure $\mathrm{MnO}_{2}$ is poor, and the equivalent series resistance of the prepared electrode is large, resulting in the specific capacitance and power density are limited. In order to increase the specific capacitance of the $\mathrm{MnO}_{2}$ electrode materials, $\mathrm{MnO}_{2}$ is usually compounded with other materials such as carbon materials or conductive polymers. ${ }^{[11-13]}$ In addition, doping the transition metal element in the $\mathrm{MnO}_{2}$ lattice is also an effective method to improve the electrochemical performance of the electrode materials. ${ }^{[8,14]}$
In this paper, $\mathrm{Ni}-\mathrm{MnO}_{2}$ electrode materials were synthesized by sol-gel method with nickel nitrate, manganese acetate and citric acid as raw materials. The structures and electrochemical performances of obtained $\mathrm{Ni}-\mathrm{MnO}_{2}$ were characterized by SEM, XRD, CV, GCD and EIS, respectively.

\section{Experimental}

\subsection{Synthesis of $\mathrm{Ni}-\mathrm{MnO}_{2}$}

$\mathrm{Ni}-\mathrm{MnO}_{2}$ was synthesized using sol-gel method. $12.26 \mathrm{~g}$ of manganese acetate and $5.25 \mathrm{~g}$ of citric acid were dissolved in small amount of deionized water. Add different proportions of nickel nitrate to manganese acetate solution according to the molar ratio in Table 1 . After completely dissolution, the mixed solution was diluted to $200 \mathrm{~mL}$, and its $\mathrm{pH}$ value was adjusted to 6 by adding aqueous ammonia. Then, the prepared solution was dehydrated in a drying oven at $80{ }^{\circ} \mathrm{C}$ for about 24 hours to obtain a wet gel, which was further dried at $110^{\circ} \mathrm{C}$ for about 6 hours to obtain a dry gel. After being taken out, it was placed in a $350{ }^{\circ} \mathrm{C}$ muffle furnace and fired for $10 \mathrm{~h}$. The product was acidified by using 2 $\mathrm{mol} / \mathrm{L} \mathrm{H}_{2} \mathrm{SO}_{4}$ at $90{ }^{\circ} \mathrm{C}$ for $2 \mathrm{~h}$. After filtration, the product was washed to neutrality and dried in a vacuum oven at $70{ }^{\circ} \mathrm{C}$ for $8 \mathrm{~h}$. The samples with different nickel molar contents were marked as NMO-1, NMO-3, NMO6, NMO-9, NMO-12 and NMO-15, respectively, as shown in Table 1 . In addition, the pure $\mathrm{MnO}_{2}$ prepared by the same procedure without adding any nickel nitrate was named MO.

\footnotetext{
* Corresponding author: Qinghao Yang@yangxjtu@hotmail.com
} 
Table 1. The molar ratios of Ni/Mn

\begin{tabular}{ccccccc}
\hline Sample & NMO-1 & NMO-3 & NMO-6 & NMO-9 & NMO-12 & NMO-15 \\
\hline Molar ratio of Ni/Mn & $1 / 100$ & $3 / 100$ & $6 / 100$ & $9 / 100$ & $12 / 100$ & $15 / 100$ \\
\hline
\end{tabular}

\subsection{Preparation of the electrode}

The synthesized $\mathrm{MnO}_{2}$ samples, acetylene black, and PTFE were mixed thoroughly at a mass ratio of 80:10:10 with a few drops of ethyl alcohol to make a fine slurry and brush coated on cleaned porous foamed nickel substrates over an area of $1 \mathrm{~cm} \times 1 \mathrm{~cm}$ and dried at in a vacuum over for $8 \mathrm{~h}$ at $80^{\circ} \mathrm{C}$. Then the porous foamed nickel substrates over an area of $1 \mathrm{~cm} \times 1 \mathrm{~cm}$ were pressed into electrodes.

\subsection{Materials characterization}

The crystal structures of the synthesized $\mathrm{MnO}_{2}$ samples were characterized by X-ray diffraction with a scan rate of $10^{\circ} / \mathrm{min}$ in scanning range of $10^{\circ}$ to $80^{\circ}$, using $\mathrm{Cu} \mathrm{K} \alpha$ as a radiation source operated at wavelength of $\lambda=$ $0.15418 \mathrm{~nm}$. The morphological studies of the samples were done by scanning electron microscopy.

\subsection{Electrochemical measurements}

Electrochemical measurements were carried out in an electrochemical workstation using a three-electrode system, with $\mathrm{Hg} / \mathrm{HgO}$ as a reference electrode, a platinum counter electrode as an auxiliary electrode, and an active material coated porous foamed nickel substrates as a working electrode in $1 \mathrm{~mol} / \mathrm{L} \mathrm{NaNO}_{3}$ electrolyte.

\section{Results and discussion}

\subsection{Structure and morphology characterizations}

Fig. 1 shows the XRD of synthesized samples MO and NMO-3. It is found that both samples showed sharp diffraction peaks at $22.01^{\circ}, 36.87^{\circ}, 42.22^{\circ}, 55.78^{\circ}$, according to all the characteristic peaks indexed to $\gamma$ $\mathrm{MnO}_{2}$ (JCPDS\#44-0142). The diffraction peaks of sample NMO-3 seem broader and weaker than those of sample MO, indicating relatively small crystal grains and low crystallinity. Since the characteristic diffraction peaks of the nickel compound are not found in the XRD pattern of sample NMO-3, the obtained products are free of nickel compound. After the nickel doping, the characteristic peak position of $\gamma-\mathrm{MnO}_{2}$ do not shift significantly, but its intensity become weak and the peaks become broad. The diffraction peak intensity of the (212) crystal plane of $\gamma-\mathrm{MnO}_{2}$ is obviously weakened, showing that nickel ions entered the lattice interior, causing $\mathrm{MnO}_{2}$ lattice distortion and grain refinement.

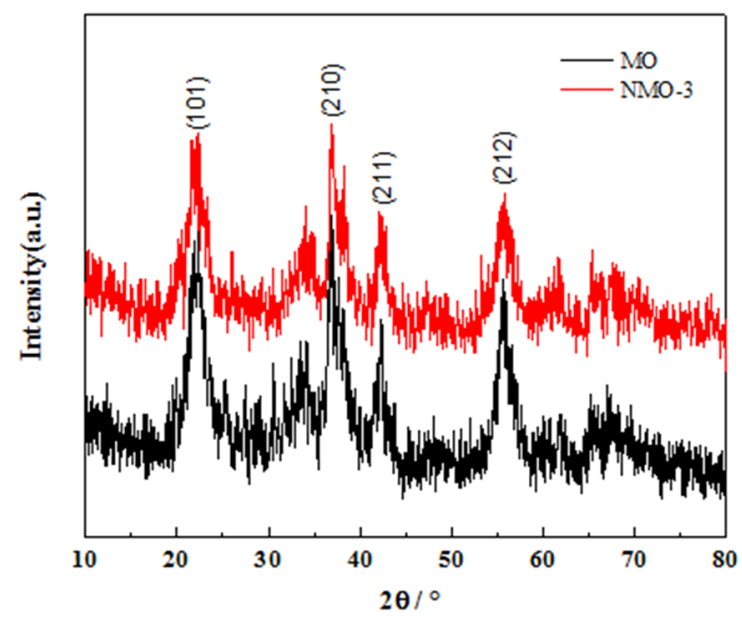

Fig. 1. XRD patterns of samples $\mathrm{MO}$ and NMO-3

Fig. 2 shows the SEM images of samples MO and NMO-3, respectively. It can be seen from the figure that both samples are composed of agglomerated spherical micro/nanoparticles. As shown in Fig. 2(a) (sample MO), massive irregular particles with the diameter of about $1 \mu \mathrm{m}$ aggregate together, forming bigger agglomerates. Compared with Fig. 2(a), the spherical particles with the diameter of about $500 \mathrm{~nm}$ in Fig. 2(b) (sample NMO-3) are smaller and more dispersed. This consequence manifests that the $\mathrm{Ni}-\mathrm{MnO}_{2}$ can effectively restrain the grans form aggregating in this experiment, which contributes to enhancing the electrochemical performance of materials.

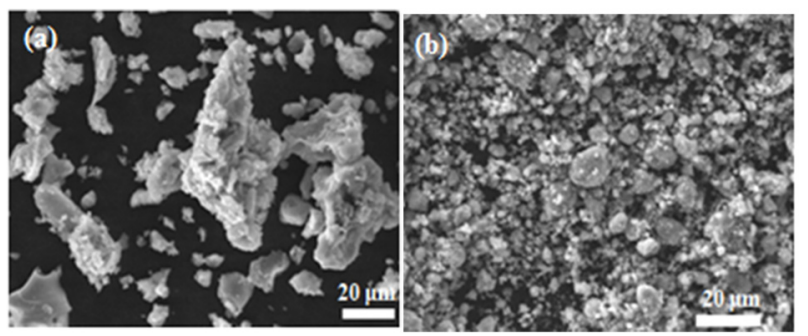

Fig. 2. SEM images of samples MO and NMO-3 (a) sample MO, (b) sample NMO-3 


\subsection{Electrochemical properties}

Fig. 3(a) shows the cyclic voltammetry (CV) curves of samples MO, NMO-1, NMO-3, NMO-6, NMO-9, NMO$12, \mathrm{NMO}-15$ at a scan rate of $5 \mathrm{mV} / \mathrm{s}$ in $1 \mathrm{~mol} / \mathrm{L} \mathrm{NaNO}_{3}$ electrolyte within the potential range of -0.1 to $0.6 \mathrm{~V}$ (vs. $\mathrm{SCE}$ ). It can be seen from the figure that the symmetry of all $\mathrm{CV}$ curves is almost close to the rectangle, indicating that the prepared electrode materials have better charge and discharge reversible capacitance characteristics. The specific capacitances of samples in Fig. 3(b) are calculated from $\mathrm{CV}$ curves using the following equation (1).

$$
C_{F}=\frac{\int I d V}{m v \Delta V}
$$

Where $C_{F}$ is the specific capacitance, $I$ is the response current density, $m$ is the mass of the active material, $v$ is the scan rate, and $\Delta V$ is the potential window of discharge. The specific capacitances of samples increases first and then decreases with the increase of the molar doping ratio of $\mathrm{Ni} / \mathrm{Mn}$, The specific capacitance of sample NMO-3 achieves a maximum value as high as $252.61 \mathrm{~F} / \mathrm{g}, \mathrm{Ni}-\mathrm{MnO}_{2}$ can significantly improve the specific capacitance of the electrode materials, which can be explained as follows. On the one hand, the manganese dioxide lattice will expand due to the incorporation of nickel element, which facilitates the

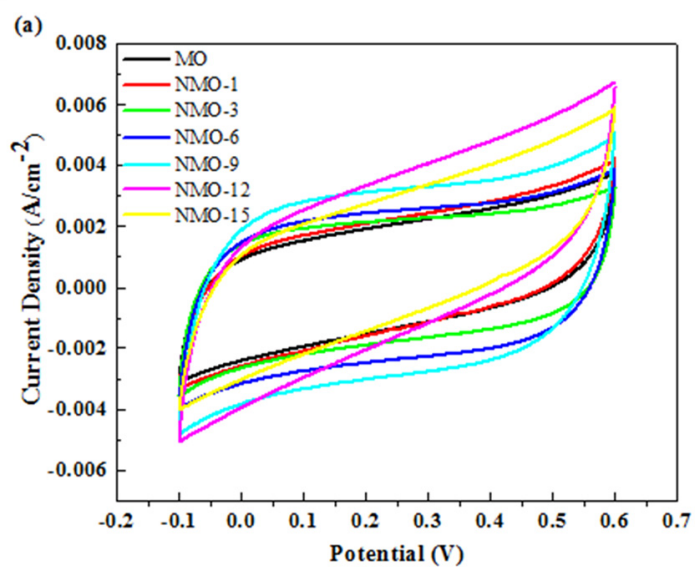

rapid insertion and extraction of electrolyte ions in the electrode materials, thereby improving the specific capacitance of the electrode materials. On the other hand, it will lead to an increase in the defects of the $\mathrm{MnO}_{2}$ lattice that the nickel element is doped into the crystal lattice to form vacancies or interstitials, which is beneficial to improve the electrochemical performance of the $\mathrm{MnO}_{2}$ electrode. In addition, if the doping of nickel is too small, the specific capacitance of the $\mathrm{MnO}_{2}$ electrode material is not significantly improved, but excessive nickel doping causes $\mathrm{MnO}_{2}$ lattice spacing to block, hindering the migration of electrolyte ions, so it is necessary to control the proper doping ratio of $\mathrm{Ni}$ and $\mathrm{Mn}$, which can make them produce synergistic effects, thereby improving the electrochemical performance of the electrode materials.

Fig. 3(c) shows the cyclic voltammetry curve (CV) of sample NMO-3 at different scan rates from 5 to 100 $\mathrm{mV} / \mathrm{s}$. The deviations from the rectangularity of $\mathrm{CV}$ curves occur with the scan rate increasing. The low scan rate leads to slow migration of ions in electrolyte through the electrode materials, thus the active materials of electrode can be fully used, achieving an ideal capacitance. However, the utilization rate of the active materials of the electrodes reduced with the scan rate increases, so that it is difficult to influence the response of the electrode potential, which lead to the CV curves start to deviate from the rectangle.

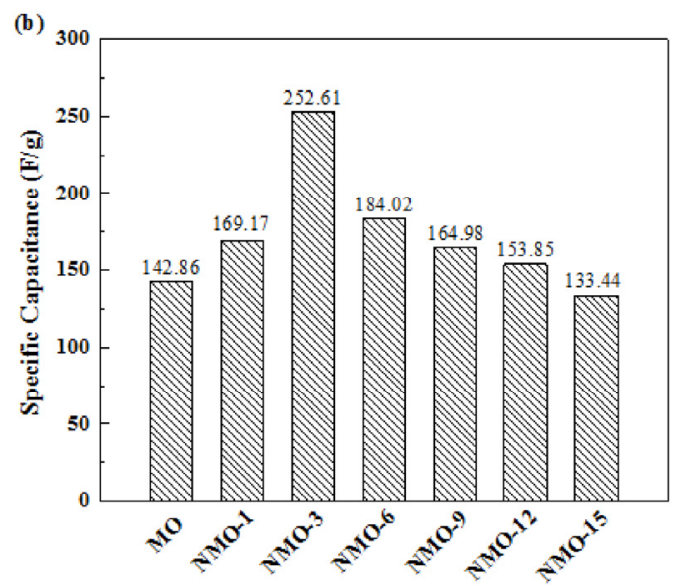

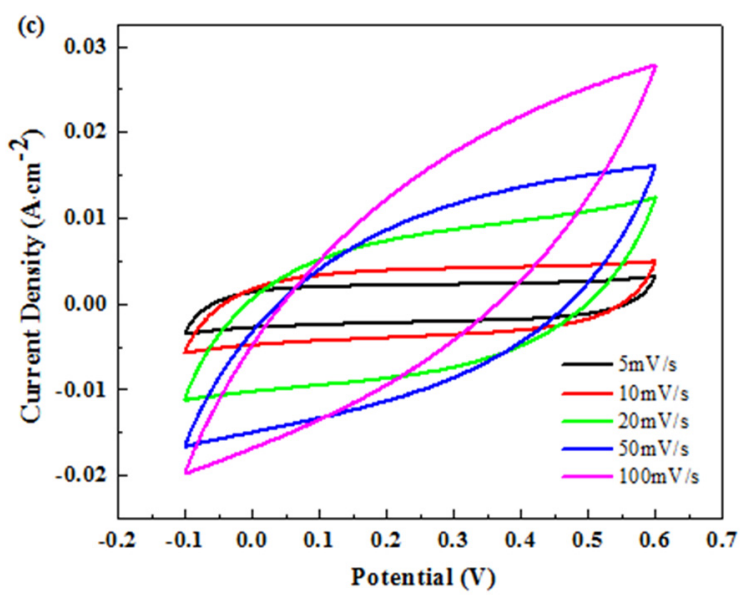

Fig. 3. (a) Cyclic voltammetry curves of different samples, (b) Specific capacitances of different samples,(c) Cyclic voltammetry of sample NMO-3 at different scan rates. 
(a)

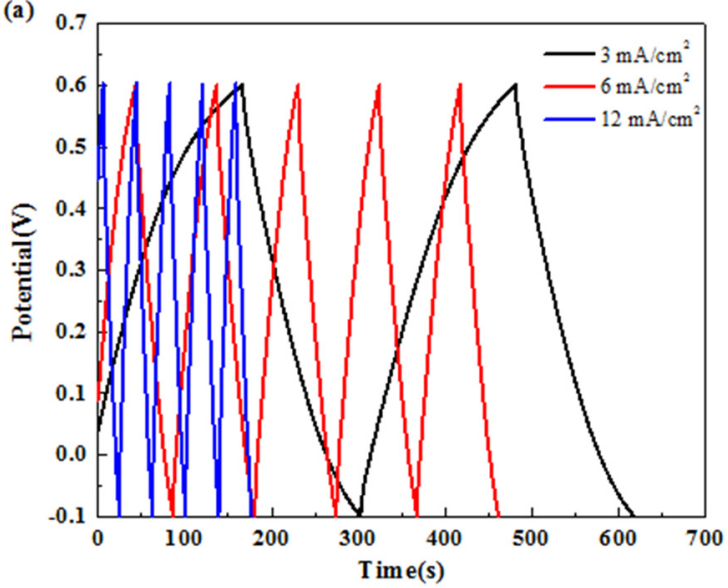

(b)

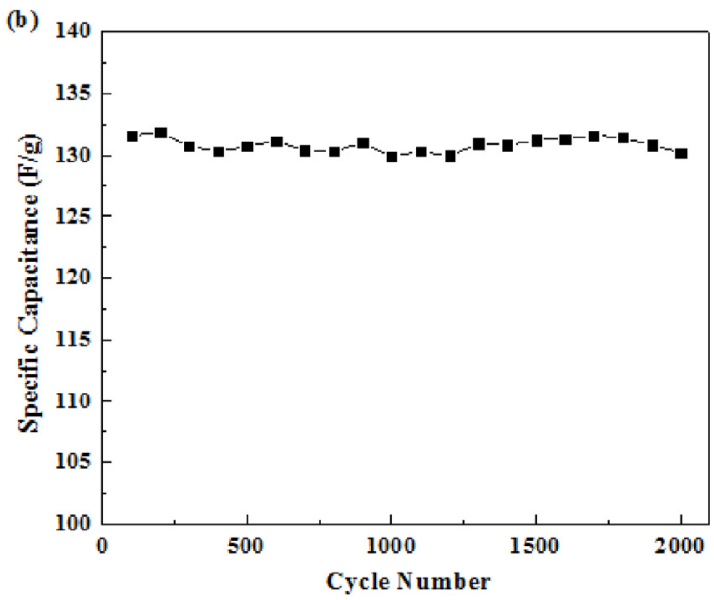

Fig. 4. (a) Charge and discharge curves of sample NMO-3 at different current densities, (b) Long-term cycling stability of sample NMO-3

In order to further explore the electrochemical performance of $\mathrm{Ni}-\mathrm{MnO}_{2}$ electrode materials, the galvanostatic charge-discharge test of sample NMO-3 is carried out in $1 \mathrm{~mol} / \mathrm{L} \mathrm{NaNO}_{3}$ electrolyte at current densities of $3 \mathrm{~mA} / \mathrm{cm}^{2}, 6 \mathrm{~mA} / \mathrm{cm}^{2}$ and $12 \mathrm{~mA} / \mathrm{cm}^{2}$. It can be seen from the Fig. 5 that all the curves are roughly symmetrical triangular, demonstrating that the electrode materials have excellent reversibility in the $1 \mathrm{~mol} / \mathrm{L}$ $\mathrm{NaNO}_{3}$ electrolyte, the voltage changes linearly with time, indicating that the storage mechanism of the electrode materials is charge transfer on the electric double layer capacitor. According to the equation (2)

$$
C_{F}=\frac{I \Delta t}{m \Delta V}
$$

Where $C_{F}$ is the specific capacitance, $I$ is the response current density, $\Delta t$ is the discharge times, $m$ is the mass of the active material, and $\Delta V$ is the potential window of discharge. The specific capacitances of sample NMO-3 are $164.62 \mathrm{~F} / \mathrm{g}, 133.93 \mathrm{~F} / \mathrm{g}$, and 107.14 $\mathrm{F} / \mathrm{g}$ at current densities of $3 \mathrm{~mA} / \mathrm{cm}^{2}, 6 \mathrm{~mA} / \mathrm{cm}^{2}$, and 12 $\mathrm{mA} / \mathrm{cm}^{2}$, respectively. As the current density increases, the specific capacitance of the electrode gradually decreases. The reason may be that the active materials cannot sufficiently perform the capacitance reaction to carry out galvanostatic charge-discharge test at a large current density. In addition, the internal resistance of the electrode causes a large voltage drop. When the current density increased from $3 \mathrm{~mA} / \mathrm{cm}^{2}$ to $12 \mathrm{~mA} / \mathrm{cm}^{2}$, the capacitance retention of the electrode reaches $65.08 \%$, indicating that the $\mathrm{Ni}-\mathrm{MnO}_{2}$ electrode materials have preeminent rate performance.

The cycle stability of electrode materials is one of the most critical factors for practical applications. The cycling stability of the sample NMO-3 is examined by charge-discharge cycling at a current density of 6 $\mathrm{mA} / \mathrm{cm}^{2}$ for 2000 cycles shown in Fig. 6. It can be seen from the figure that the specific capacitance is unstable during the first 300 cycles. Because the electrode material is unstable so that some active substances fall off during the pre-activation process. After a period of time, the specific capacitance of the electrode reaches a steady state. The specific capacity retention of the electrode material is about $74.36 \%$ after 2000 cycles, this result indicates that the $\mathrm{Ni}-\mathrm{MnO}_{2}$ electrode to meet the requirements of both long cycle lifetime and favourable rate capability.

Electrochemical impedance spectroscopy (EIS) is performed to investigate the resistive components of the products involved in the electrochemical system. Fig. 7 shows the Nyquist plots of samples MO and NMO-3, whose the equivalent circuit model is as shown in inset of (a). This equivalent circuit consists of equivalent series resistance $\left(R_{e}\right)$, double layer capacitance (CPE), charge transfer resistance $\left(R_{c t}\right)$, Warburg impedance $(\mathrm{W})$, diffusion capacitance $(\mathrm{C})$, and the diffusion resistance $\left(R_{d}\right)$. The illustration (b) is a partial enlargement of their high frequency region. It can be seen from the figure that the both samples have obvious capacitive reactance arc in the high frequency region, and the $R_{e}$ of the samples $\mathrm{MO}$ and NMO-3 are almost the same, approximately $2.68 \Omega$. The $R_{c t}$ of sample NMO-3 (1.89 $\Omega$ ) estimated from the diameter of the semicircle is smaller than that of the sample of MO (2.12 $\Omega$ ), demonstrating that the $\mathrm{Ni}-\mathrm{MnO}_{2}$ has a reduced charge transfer resistance and thus has better conductivity. In the low frequency region, the slope of the sample MO is much smaller than that of the sample NMO-3, indicating that the $R_{d}$ of nickeldoped $\mathrm{MnO}_{2}$ is smaller, which is beneficial to rapid ion diffusion transfer, so that it has a better capacitance performance.

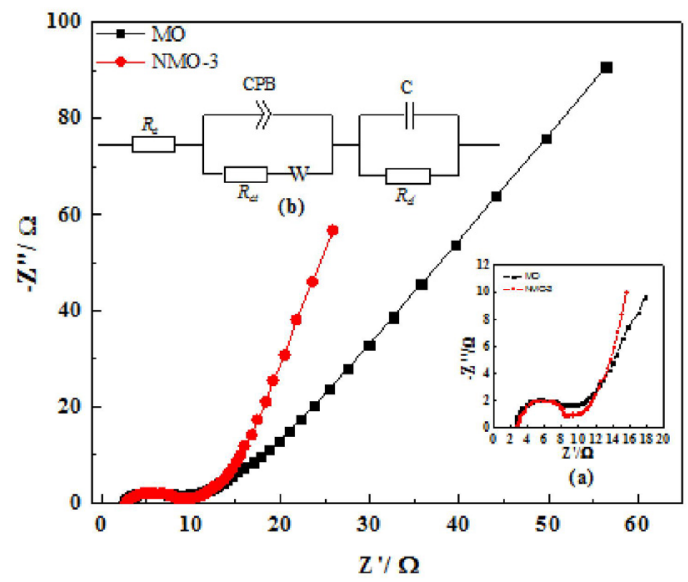

Fig. 5. Nyquist impedance spectra of samples $\mathrm{MO}$ and NMO-3 


\section{Conclusion}

Nickel-doped $\mathrm{MnO}_{2}$ electrode materials have been synthesized by sol-gel method. Adding nickel does not affect the crystal structure $\left(\gamma-\mathrm{MnO}_{2}\right)$, but alters the micromorphology. In order to evaluate the capacitive properties of $\mathrm{MnO}_{2}$ with different nickel contents, CV and GCD measurements are performed. When the molar ratio of $\mathrm{Ni} / \mathrm{Mn}$ is 3/100, the sample NMO-3 reaches $252.61 \mathrm{~F} / \mathrm{g}$ at scanning rate of $5 \mathrm{mV} / \mathrm{s}$, which is $76.82 \%$ higher than undoped $\mathrm{MnO}_{2}$. After 2000 cycles of charge and discharge, the retention rate of specific capacity is about $74.36 \%$. Moreover, this sample also exhibits excellent electrochemical stability and reversibility. These results from the EIS indicate that nickel doping can reduce the charge transfer resistance and diffusion resistance of $\mathrm{MnO}_{2}$, thus to improve the capacitance performances of the materials. In summary, doping an appropriate amount of nickel can effectively improve the electrochemical performance of $\mathrm{MnO}_{2}$.

\section{Acknowledgments}

This work was financially supported by The Natural Science Basic Research Plan in Shaanxi Province of China (2016JQ5078), the Key R \& D Program of Shaanxi Province, China (2017GY-133) and The Special Research Project of Shaanxi Education Department (17JK0512).

\section{References}

1. S.D. Kim, D. Lim, D. Nam, D. Seo, S. E. Shim, S.H. Baeck. J. Nanosci. Nanotechol. 17, 79477951(2017).

2. J. Wang, B. Wang. Bull. Korean Chem. Soc.39, 386-341(2018).

3. J.W. Wang, Y. Chen, B.Z. Chen. j.jallcom. 688, 184-197(2016).

4. L. Li, Z.A. Hu, N. An, Y.Y. Yang, Z.M. Li, H.Y. Wu. J.Phys.Chem.C. 118, 22865-22872(2014).

5. A.M. Obeidat, M.A. Gharaibeh, M. Obaidat. j.est. 13, 123-128(2017).

6. Y.S. Lim, Y.P. Tan, H.N. Lim, N.M. Huang, W.T. Tan, M.A. Yarmo, C.Y. Yin. Ceramics International, 2014, 40(3): 3855-3864.

7. D. Xiang, L. Yin, C. Wang, L. Zhang. j. energy. 106, 103-111(2016).

8. D. Shanbhag, K. Bindu, A.R. Aarathy, M. Ramesh, M. Sreejesh, H.S. Nagaraja. j. mtener. 4, 6674(2017).

9. J. Gao, X. Wang, Y. Zhang, J. Liu, Q. Lu, M. Chen, Y. Bai. j.electacta. 192, 234-242(2016).

10. Xiangcang Ren, Chuanjin Tian, Sa Li, Yucheng Zhao, Chang-An Wang. Facile synthesis of tremellalike $\mathrm{MnO}_{2}$ and its application as supercapacitor electrodes [J]. Frontiers of Materials Science, 2015, 9(3): 234-240.
11. W. Gong, B. Fugetsu, Z. Wang, I. Sakata, L. Su, X. Zhang, H. Ogata, M. Li, C. Wang, J. Li, J. OrtizMedina, M. Terrones, M. Endo. Communications Chemistry, 1, 1-8(2018).

12. Q. Wu, M. Chen, S. Wang, X. Zhang, L. Huan, G. Diao. j. cej. 304. 29-38(2016).

13. S.C. Lin, Y.T. Lu, Y.A. Chien, J.A Wang, T.H. You, Y.S. Wang, C.W. Lin, C.M. Ma, C. Hu. j. jpowsour. 362, 258-269(2017).

14. G. Wang, Z. Ma, G. Zhang, C. Li, G. Shao. Electrochimica Acta, 182, 1070-1077(2015). 